\title{
Antibodies against electronegative LDL inhibit atherosclerosis in LDLr-/- mice
}

\author{
D.M. Grosso ${ }^{1}$, S. Ferderbar ${ }^{1}$, A.C.B.A. Wanschel ${ }^{2}$, M.H. Krieger ${ }^{2}$, M.L. Higushi ${ }^{3}$ and \\ D.S.P. Abdalla ${ }^{1}$
}

1Departamento de Análises Clínicas e Toxicológicas, Faculdade de Ciências Farmacêuticas, Universidade de São Paulo, São Paulo, SP, Brasil

${ }^{2}$ Departamento de Fisiologia e Biofísica, Instituto de Biologia, Universidade Estadual de Campinas, Campinas, SP, Brasil

${ }^{3}$ Instituto do Coração, Faculdade de Medicina, Universidade de São Paulo, São Paulo, SP, Brasil

Correspondence to: D.S.P. Abdalla, Faculdade de Ciências Farmacêuticas, USP, Av. Prof. Lineu

Prestes, 580, 05508-900 São Paulo, SP, Brasil

Fax: +55-11-3813-2197. E-mail: dspa@usp.br

\begin{abstract}
In order to determine the effect of antibodies against electronegative low-density lipoprotein LDL(-) on atherogenesis, five groups of LDL low receptor-deficient (LDLr-/-) mice (6 per group) were immunized with the following antibodies (100 $\mu \mathrm{g}$ each): mouse anti-LDL(-) monoclonal IgG2b, rabbit anti-LDL(-) polyclonal IgG or its Fab fragments and mouse irrelevant monoclonal $\mathrm{IgG}$ and non-immunized controls. Antibodies were administered intravenously one week before starting the hypercholesterolemic diet (1.25\% cholesterol) and then every week for 21 days. The passive immunization with anti-LDL(-) monoclonal IgG2b, polyclonal antibody and its derived Fab significantly reduced the cross-sectional area of atherosclerotic lesions at the aortic root of LDLr-/- mice $\left(28.8 \pm 9.7,67.3 \pm 17.02,56.9 \pm 8.02 \mu \mathrm{m}^{2}\right.$ (mean \pm SD), respectively) compared to control $\left(124.9 \pm 13.2 \mu \mathrm{m}^{2}\right)$. Vascular cell adhesion molecule-1 protein expression, quantified by the KS300 image-analyzing software, on endothelium and the number of macrophages in the intima was also decreased in aortas of mice treated with anti-LDL(-) monoclonal antibody ( $3.5 \pm 0.70$ per field $x 10)$ compared to controls $(21.5 \pm 3.5$ per field $x 10)$. Furthermore, immunization with the monoclonal antibody decreased the concentration of $\mathrm{LDL}(-)$ in blood plasma (immunized: $1.0 \pm 1.4$; control: $20.5 \pm 3.5 \mathrm{RLU}$ ), the amount of cholesterol oxides in plasma (immunized: $4.7 \pm 2.7$; control: $15.0 \pm 2.0 \mathrm{pg} \mathrm{COx} / \mathrm{mg}$ cholesterol) and liver (immunized: $2.3 \pm 1.5$; control: $30.0 \pm 26.0 \mathrm{pg} \mathrm{COx} / \mathrm{mg}$ cholesterol), and the hepatic content of lipid hydroperoxides (immunized: $0.30 \pm 0.020$; control: $0.38 \pm 0.15 \mathrm{ng} / \mathrm{mg}$ protein). In conclusion, antibodies against electronegative LDL administered intravenously may play a protective role in atherosclerosis.
\end{abstract}

Key words: Minimally modified LDL; Passive immunization; Monoclonal antibody; Atherogenesis

Research supported by FAPESP (\#03/02435-2, pos-doctoral scholarship to D.M. Grosso) and Instituto do Milênio Redoxoma/CNPq (\#420011/2005 to D.S.P. Abdalla).

Received June 9, 2008. Accepted December 8, 2008

\section{Introduction}

Modification of low-density lipoprotein (LDL) plays a key role in atherosclerosis. A minimally modified circulating electronegative LDL subfraction, denoted LDL(-), is increased in hypercholesterolemia and diabetes and has been implicated in atherosclerosis progression $(1,2)$. LDL(-) particles have lower antioxidant content, increased lipid peroxidation products, as well as conformational al- terations of apoB $(3,4)$. LDL(-) is cytotoxic to cultured endothelial cells (5), promotes increased leukocyte recruitment for inducing the release of IL-8 and monocyte chemotactic protein 1 (6), impairs angiogenesis (7), and has less affinity for the LDL receptor $(3,8)$. Intravenous injection of immunoglobulins is used as a therapy for autoimmune and systemic inflammatory diseases $(9,10)$. In contrast, it has been suggested that antibodies reactive to oxidized LDL (ox-LDL) may contribute to the pathogen- 
esis of atherosclerosis (11). However, anti-ox-LDL IgM antibodies may protect against atherosclerosis possibly because they can scavenge the ox-LDL particles (12). We report here that the passive immunization with xenogeneic polyclonal antibodies, xenogeneic Fab fragments, and allogeneic monoclonal antibodies IgG reactive to LDL(-) significantly reduced atherosclerosis in LDLr-/- mice.

\section{Material and Methods}

\section{Polyclonal antibodies reactive to $\mathrm{LDL}(-)$}

New Zealand rabbits were immunized by intramuscular injection every 2 weeks for 3 months with $50 \mu \mathrm{g}$ LDL(-) incorporated in Freund's complete adjuvant for the first injection and in incomplete Freund's adjuvant for subsequent injections. LDL(-) was purified by fast protein liquid chromatography (13). After purification, 1.0 mM EDTA, 5.0 $\mathrm{mM}$ phenylmethylsulfonyl fluoride, $10.0 \mu \mathrm{M}$ benzamidine, $10.0 \mu \mathrm{g} / \mathrm{mL}$ aprotinine and $100.0 \mu \mathrm{M}$ butylated hydroxytoluene were added to the LDL(-) preparation and was maintained at $4^{\circ} \mathrm{C}$. The production of anti-LDL(-) polyclonal antibody was monitored by ELISA. Antibodies were purified from rabbit serum by affinity chromatography in a protein $G$ column (Hi Trap Protein-G, Pharmacia, Biotech, USA) (14). ELISAs were carried out $(15,16)$ using a SpectroCount analyzer (Canberra Company, USA). Plates (EIA/RIA, Costar, USA) were coated with $1 \mu \mathrm{g} / \mathrm{mL}$ purified native LDL and the anti-LDL(-) monoclonal antibody was added after previously blocking the microplate wells with defatted milk. The antibodies were cleaved by papain to obtain the Fab fragments (17). Fragmentation was confirmed by $10 \%$ SDSPAGE on vertical slab gels according to Laemmli (18) with silver nitrate staining (data not shown).

\section{Purification of monoclonal antibody}

The IgG2b anti-LDL(-) monoclonal antibody (MAb 3D1036) was obtained in our laboratory as described (3). Briefly, the antibodies were obtained from the ascitic fluid induced in BALB/c mice (6 to 10 weeks old) injected with Pristane (Sigma, USA) before the inoculation of the 3D1036 hybridoma cells secreting the anti-LDL(-) MAb. Ten days after this inoculation, the MAb was purified from the ascitic fluid by affinity chromatography in a protein $G$ column (Hi Trap Protein-G, Pharmacia, Biotech, Sweden). The MAb 3D1036 recognizes an epitope present in minimally modified LDL particles as previously reported by Damasceno et al. (2).

\section{Passive immunization}

Female C57BL/6 LDL receptor knockout mice (3 months old) were purchased from Jackson Laboratories
(USA). The following groups, with 6 animals each, were studied: group 1 (controls), treated with PBS; group 2, treated with $100 \mu \mathrm{g}$ of an irrelevant MAb (IgG2b anti-18 kDa peptides of Taenia crassiceps); group 3, treated with rabbit IgG polyclonal antibody $(100 \mu \mathrm{g})$ against LDL(-); group 4, treated with Fab fragments $(100 \mu \mathrm{g})$ derived from the rabbit polyclonal antibody reactive to $\operatorname{LDL}(-)$; group 5, treated with IgG2b monoclonal antibody (100 $\mu \mathrm{g})$ against LDL(-). Antibodies were administered intravenously once one week before starting the $1.25 \%$ cholesterol-enriched diet and then every week for 21 days.

All procedures were in accordance with recomendations of the Institutional Committee for Ethics in Animal Experimentation (CEEA/IB, UNICAMP, protocol \#521-1, Brazil), in agreement with the guidelines of the Brazilian College for Animal Experimentation.

Tissue preparation and histomorphometry of aortic root lesions

The heart was perfused with PBS and then with $10 \%$ PBS-buffered formaldehyde. The heart and aorta were excised and fixed in 10\% formaldehyde for at least 2 days, and then embedded in 5, 10, and $25 \%$ gelatin and frozen in mounting medium (Tissue-Tek OTC compound, Sakura Finetek, USA). The aortic root in the heart was sectioned proximally to distally in $10 \mu \mathrm{m}$ starting from the semilunar valves. The area of the atherosclerotic lesion was reported as the sum of the lesion in 6 equidistant sections $(80 \mu \mathrm{m})$ from each other in an aortic root length of $400 \mu \mathrm{m}$. Results from 6 mice/group are reported as mean $\mu \mathrm{m}^{2} \pm \mathrm{SD}$. To quantify the ross-sectional area of the oil red O-stained lesions in the aortic root, processing and staining were carried out as described (19), using the Image Pro Plus software (version 3.0) for image analysis (Media Cybernetics, USA). All analyses were double-blind and carried out independently by two observers.

\section{Immunohistochemical and histochemical analyses}

To evaluate the vascular cell adhesion molecule-1 (VCAM-1), the remaining thoracic and abdominal aortas were mounted with Tissue-Tek OTC compound, frozen in isopentane and embedded in paraffin. VCAM-1 was detected with an anti-VCAM antibody (Santa Cruz Biotechnology, $\mathrm{H}-276$, USA) (20). VCAM-1 staining was quantified using an image-analyzing software (KS300, Kontron, Germany). The histochemical analysis of the aorta was done in $5-\mu \mathrm{m}$ thick tissue sections stained with hematoxylin/eosin. The number of foam cells was estimated as described (21).

Detection of LDL(-) in blood plasma and autoantibodies At the end of the experiment, blood was collected from 
the ocular-plexus and plasma was obtained by centrifugation. LDL(-) was determined by ELISA with Fab fragments derived from rabbit anti-LDL(-) polyclonal IgG as the capture antibody. A biotinylated anti-LDL(-) monoclonal antibody was added as secondary antibody and streptavidinhorseradish peroxidase conjugate was used for quantitation. The positive reaction was evaluated by chemiluminescence and the concentration of LDL(-) was determined using a standard curve made with purified LDL(-) (22).

Anti-LDL(-) autoantibodies were determined by direct ELISA. Plasma samples ( $50 \mu \mathrm{L} /$ well) previously diluted in PBS (1:50) were assayed. An anti-mouse lgG/horseradish peroxidase conjugate (Bio-Rad, USA) was used for detection and quantitation using standard procedures. The reaction was evaluated colorimetrically at $492 \mathrm{~nm}$ using a SpectroCount analyzer (Canberra Company). All experiments were carried out in triplicate.

\section{Analysis of lipid peroxidation}

Lipid hydroperoxides were extracted from the liver and the cholesterol oxides (COx) were extracted from both liver and plasma of LDLr-/- mice as described by Pereira et al. (23).

\section{Statistical analysis}

ANOVA and the Tukey-Kramer test were used to analyze the data statistically. All values are reported as mean \pm SD. Statistical significance was considered to be $\mathrm{P}<0.05$.

\section{Results}

\section{Atherosclerotic lesions}

The passive immunization of LDLr-/- mice with the antiLDL(-) monoclonal (IgG2b isotype) and IgG polyclonal (whole or its Fab fragments) antibodies decreased the cross-sectional area of atherosclerotic lesions at the aortic root compared with controls (Figure 1). Immunization with the anti-LDL(-) MAb did not change the total plasma cholesterol concentration compared to the control group (immunized: $46.6 \pm 18.7$; control: $60.5 \pm 13.6 \mathrm{mg} / \mathrm{mL}$ total cholesterol). The protective effect of the anti-LDL(-) monoclonal IgG2b was greater than that of the polyclonal IgG and irrelevant monoclonal antibody for reducing both the cross-sectional area (Figure 1A) and the number of foam cells in the atherosclerotic lesions (Figure 1B). Figure 2 shows the oil red-stained sections of atherosclerotic lesions at the aortic root of mice immunized with the same antibodies as shown in Figure 1.

Expression of vascular cell adhesion molecule-1

Mice receiving the Fab fragments derived from the rabbit anti-LDL(-) polyclonal antibody showed the largest decrease of VCAM-1 expression in aorta sections than those receiving the whole antibody and non-immunized control mice (Figure 3).

\section{Concentration of free LDL(-) and autoantibodies}

The passive immunization of LDLr-/- mice with antiLDL(-) monoclonal IgG2b decreased the circulating levels of free LDL(-) and also increased free anti-LDL(-) IgG antibodies in relation to the non-immunized controls and irrelevant antibody (Figure 4A and B). In contrast, immunization with the anti-LDL(-) polyclonal IgG enhanced the levels of free LDL(-) and decreased the levels of free antiLDL(-) IgG antibodies in blood plasma compared with the non-immunized controls. The administration of Fab fragments derived from the anti-LDL(-) polyclonal IgG antibody did not affect any of the parameters evaluated when compared with the control non-immunized mice.
A

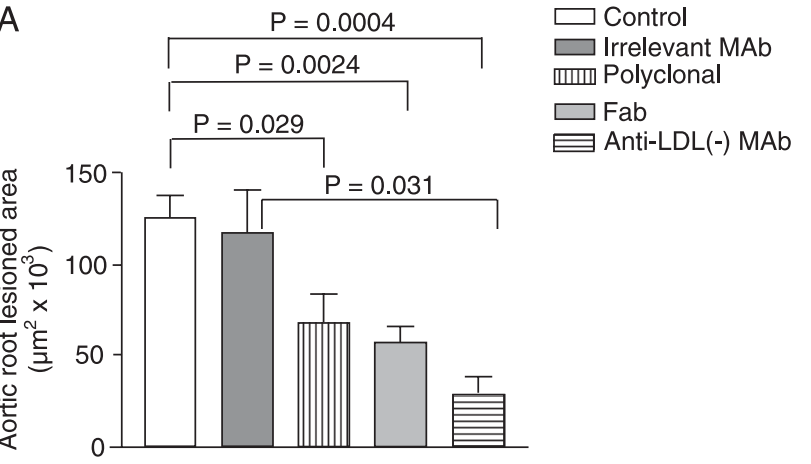

B

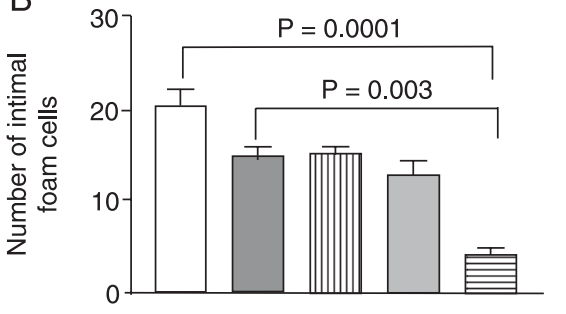

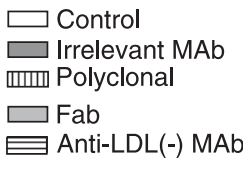

Figure 1. Atherosclerotic lesions of low-density lipoprotein receptor-deficient (LDLr-/-) mice treated with antibodies against $\mathrm{LDL}(-)$. $A$, Cross-sectional area of atherosclerotic lesions at the aortic root of LDLr-/- mice; $B$, number of foam cells in the subintimal layer of atherosclerotic lesions of LDLr-/- mice treated or not with anti-LDL(-) monoclonal antibody (MAb, $100 \mu \mathrm{g})$, irrelevant Mab $(100 \mu \mathrm{g})$, rabbit polyclonal anti-LDL(-) antibody (100 $\mu \mathrm{g})$ and Fab fragments from rabbit anti-LDL(-) polyclonal antibody $(100 \mu \mathrm{g})$. $\mathrm{P}<0.05$, ANOVA followed by the Tukey-Kramer test. 
Figure 2. Atherosclerotic lesions in aortic valve of low-density lipoprotein receptor-deficient (LDLr-/-) mice. Aorta sections of $A$, control mice; $B$, mice treated with anti-LDL(-) polyclonal antibody $(100 \mu \mathrm{g}) ; C$, mice treated with Fab fragments from anti-LDL(-) polyclonal antibody $(100 \mu \mathrm{g}) ; D$, mice treated with anti-LDL(-) monoclonal antibody $(100 \mu \mathrm{g})$. The sections were stained with oil red $\mathrm{O}$ and the arrows indicate the build-up of plaque within the aorta. Magnification: $4 X$ and $40 X$.
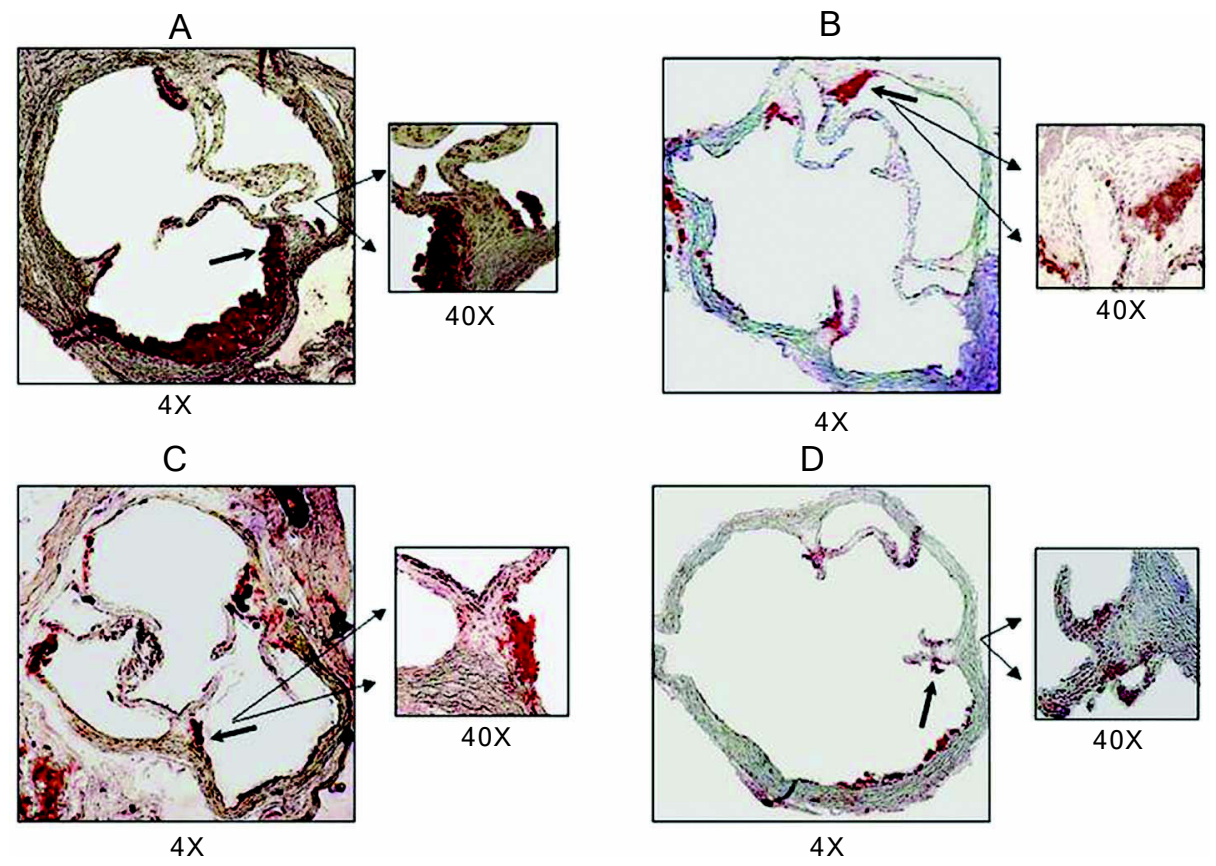

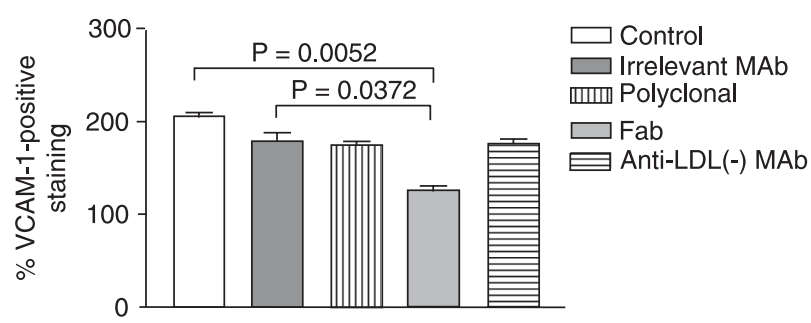

Figure 3. Immunohistochemistry staining of vascular cell adhesion molecule-1 (VCAM-1) in sections of the aorta of low-density lipoprotein receptor-deficient (LDLr-/-) mice not treated or treated with irrelevant monoclonal antibody (MAb, $100 \mu \mathrm{g}$ ), anti-LDL(-) MAb $(100 \mu \mathrm{g})$, rabbit anti-LDL(-) polyclonal antibody $(100 \mu \mathrm{g})$ or Fab fragments from rabbit anti-LDL(-) polyclonal antibody (100 $\mu \mathrm{g})$. Percent of VCAM-1-positive staining on aorta sections was evaluated using image-analyzing software (KS300, Kontron). P $<0.05$, ANOVA followed by the Tukey-Kramer test.
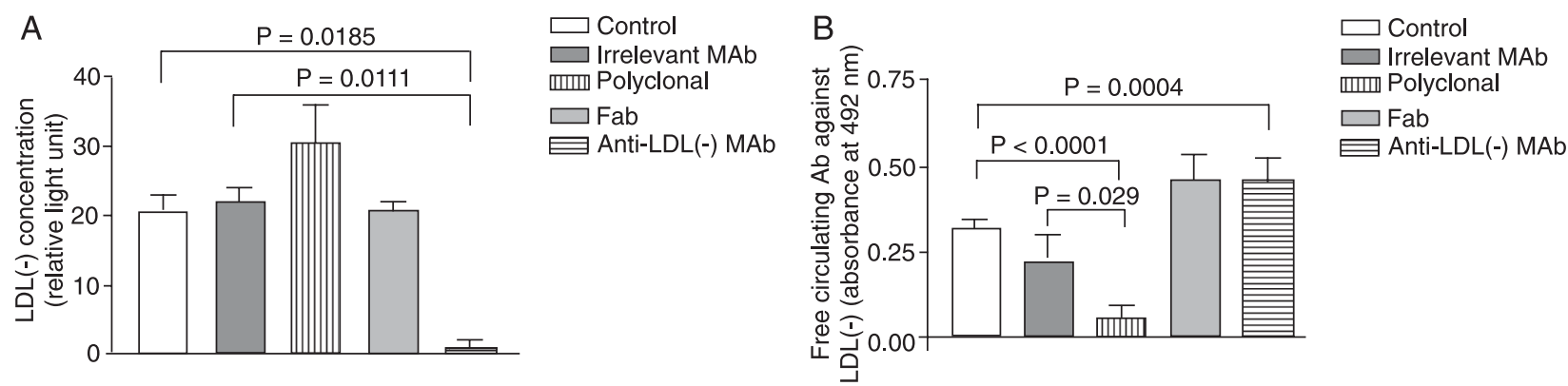

Figure 4. Determination of electronegative low-density lipoprotein [LDL(-)] and its autoantibodies in blood plasma of low-density lipoprotein receptor-deficient (LDLr-/-) mice not treated or treated with irrelevant monoclonal antibody (MAb, 100 $\mu$ g), anti-LDL(-) MAb $(100 \mu \mathrm{g})$, rabbit anti-LDL(-) polyclonal antibody $(100 \mu \mathrm{g})$ or Fab fragments from rabbit anti-LDL(-) polyclonal antibody (100 $\mu \mathrm{g})$. $A$, Concentration of $\operatorname{LDL}(-)$. $B$, Levels of free circulating antibodies $(\mathrm{Ab})$ reactive to $\mathrm{LDL}(-) . \mathrm{P}<0.05$, ANOVA followed by the Tukey-Kramer test. 


\section{Lipid peroxidation}

Passive immunization of LDLr-/- mice with the antiLDL(-) IgG2b MAb reduced the concentrations of COx in plasma (immunized: $4.7 \pm 2.7$; irrelevant control $14.7 \pm$ 2.1; control: $15.0 \pm 2.0 \mathrm{pg} \mathrm{COx} / \mathrm{mg}$ cholesterol) and liver by 70 and $92 \%$, respectively (immunized: $2.3 \pm 1.5$; irrelevant control $31 \pm 26$; control: $30.0 \pm 26.0$ pg COx/mg cholesterol), as well as $21 \%$ of hepatic lipid hydroperoxides (immunized: $0.30 \pm 0.020$; irrelevant control: $0.40 \pm$ 0.16 ; control: $0.38 \pm 0.15 \mathrm{ng} / \mathrm{mg}$ protein) compared with non-immunized control mice.

\section{Discussion}

The most important finding of this study was that passive immunization of LDLr-/- mice with monoclonal and polyclonal antibodies against LDL(-) decreases the crosssectional area of lipid-stained atherosclerosis plaques in the aortic root. Our data showed that the monoclonal antibody (IgG2b) was more atheroprotective even when compared with the polyclonal antibody. This may be related to the recognition of the rabbit-derived polyclonal antibody as non-self by murine immune system.

LDLr-/- mice treated with anti-LDL(-) monoclonal antibody had lower levels of circulating free LDL(-) than the non-immunized mice or mice immunized with irrelevant monoclonal antibody. Thus, considering that passive immunization with IgG2b anti-LDL(-) monoclonal antibody had a protective effect on atherosclerotic plaque development, it is possible that the decreased levels of free LDL(-) in blood plasma were due to the formation of immune complexes between LDL(-) and the monoclonal antibody injected in mice. We also observed an inverse relationship between circulating free LDL(-) and free antiLDL(-) antibodies in mice treated with anti-LDL(-) monoclonal antibody. This high level of free IgG antibodies reactive to LDL(-) probably reflects endogenous autoantibodies plus the exogenous injected antibody since an anti-mouse IgG-conjugate was used in ELISA. This validated the passive immunization with this monoclonal antibody, since the mean half-life of mouse IgG is 14 days and a considerable amount of free anti-LDL(-) monoclonal antibody would be expected to remain in the circulation 7 days after the last injection. In contrast, for mice treated with rabbit anti-LDL(-) polyclonal antibodies, an immune response of these animals against the Fc portion of rabbit IgG could contribute to induce the generation of mouse antibodies against rabbit IgG-LDL(-) immune complexes. Thus, these high levels of antibodies could affect the detection of free anti-LDL(-) antibodies by ELISA in the plasma of these mice. The administration of
Fab fragments derived from the rabbit anti-LDL(-) polyclonal antibody did not affect the concentration of free autoantibodies reactive to LDL(-). This was probably because Fab fragments retain the ability to bind to LDL(-) epitopes while they lose the binding region to Fc of mouse immunoglobulins. Thus, the free mouse autoantibodies remain in circulation. The presence of anti-LDL(-) autoantibodies in non-immunized LDLr-/- mice indicates that the endogenous humoral immune response was not atheroprotective since in these animals the atherosclerotic lesions were more accentuated compared with immunized mice. Another possible explanation is that the titer of endogenous antibodies was not enough and once $400 \mu \mathrm{g}$ of additional anti-LDL(-) was added by adoptive transfer an atheroprotective effect was attained.

In vivo studies have suggested that macrophage death in early lesions decreases macrophage burden and slows lesion progression $(24,25)$. The live macrophages may promote late lesional complications by secreting inflammatory mediators (26). In the present study, mice treated with anti-LDL(-) monoclonal IgG2b had less foam cells in the subintimal layer of atherosclerotic lesions compared with control mice. These observations are consistent with other studies showing that immunization with human IgG1 against malondialdehyde (MDA)-peptide sequences reduced atherosclerosis in apoE-/- mice associated with a decreased number of macrophages in atherosclerotic plaques (27). Probably the monoclonal antibody antiLDL(-) neutralized circulating LDL(-) and avoided its effects on endothelium including the release of monocyte chemotactic factors, the entrance of these cells into the artery wall and their differentiation to macrophages.

The removal of LDL(-) by anti-LDL(-) monoclonal $\lg$ G2b decreased the formation of lipid peroxidation products in plasma and liver of LDLr-/- mice, suggesting an additional atheroprotective effect of this passive immunization. Moreover, the decreased concentration of cholesterol oxides in plasma of anti-LDL(-) monoclonal antibody-treated mice may also be a consequence of LDL(-) removal from blood circulation since these minimally modified particles have an increased content of lipid peroxidation products (5).

The expression of adhesion molecules in arterial endothelial cells occurs during the early phases of diet-induced atherogenesis $(28,29)$. In the present study, VCAM-1 expression was reduced after treating LDLr-/- mice with the Fab fragment derived from the anti-LDL(-) polyclonal antibody. One reason is that endothelial cells express Fc gamma receptors (30) and, thus, the absence of the Fc portion in the Fab fragment would not induce the activation of endothelial cells leading to decreased VCAM expression. 
We have shown for the first time that antibodies against LDL(-) administered intravenously can play a protective role in atherosclerosis. Although the mechanisms involved in this atheroprotection have not yet been elucidated, our results point to the importance of immune responses against oxidized LDL in atherosclerosis and the possibility that the antibodies against modified LDL could be used to assess disease activity, as well as a therapeutic strategy for the prevention of atherosclerosis.

\section{References}

1. Oliveira JA, Sevanian A, Rodrigues RJ, Apolinario E, Abdalla DS. Minimally modified electronegative LDL and its autoantibodies in acute and chronic coronary syndromes. Clin Biochem 2006; 39: 708-714.

2. Damasceno NR, Sevanian A, Apolinario E, Oliveira JM, Fernandes I, Abdalla DS. Detection of electronegative low density lipoprotein (LDL-) in plasma and atherosclerotic lesions by monoclonal antibody-based immunoassays. Clin Biochem 2006; 39: 28-38.

3. Avogaro P, Bon GB, Cazzolato G. Presence of a modified low density lipoprotein in humans. Arteriosclerosis 1988; 8: 79-87.

4. Avogaro P, Cazzolato G, Bittolo-Bon G. Some questions concerning a small, more electronegative LDL circulating in human plasma. Atherosclerosis 1991; 91: 163-171.

5. Hodis HN, Kramsch DM, Avogaro P, Bittolo-Bon G, Cazzolato G, Hwang J, et al. Biochemical and cytotoxic characteristics of an in vivo circulating oxidized low density lipoprotein (LDL-). J Lipid Res 1994; 35: 669-677.

6. De Castellarnau C, Sanchez-Quesada JL, Benitez S, Rosa $R$, Caveda L, Vila L, et al. Electronegative LDL from normolipemic subjects induces IL-8 and monocyte chemotactic protein secretion by human endothelial cells. Arterioscler Thromb Vasc Biol 2000; 20: 2281-2287.

7. Chen $\mathrm{CH}$, Jiang T, Yang JH, Jiang W, Lu J, Marathe GK, et al. Low-density lipoprotein in hypercholesterolemic human plasma induces vascular endothelial cell apoptosis by inhibiting fibroblast growth factor 2 transcription. Circulation 2003; 107: 2102-2108.

8. Benitez S, Ordonez-Llanos J, Franco M, Marin C, Paz E, Lopez-Miranda J, et al. Effect of simvastatin in familial hypercholesterolemia on the affinity of electronegative lowdensity lipoprotein subfractions to the low-density lipoprotein receptor. Am J Cardiol 2004; 93: 414-420.

9. Dwyer JM. Manipulating the immune system with immune globulin. N Engl J Med 1992; 326: 107-116.

10. Kaveri SV, Dietrich G, Hurez V, Kazatchkine MD. Intravenous immunoglobulins (IVIg) in the treatment of autoimmune diseases. Clin Exp Immunol 1991; 86: 192-198.

11. Palinski W, Witztum JL. Immune responses to oxidative neoepitopes on LDL and phospholipids modulate the development of atherosclerosis. J Intern Med 2000; 247: 371380.

12. Shaw PX, Horkko S, Tsimikas S, Chang MK, Palinski W, Silverman GJ, et al. Human-derived anti-oxidized LDL au-

\section{Acknowledgments}

The authors thank Nágila R.D. Teixeira (Faculdade de Saúde Pública, Universidade de São Paulo, São Paulo, SP, Brazil) and Suely A.P. Palomino (Instituto do Coração, Faculdade de Medicina, Universidade de São Paulo, São Paulo, SP, Brazil) for technical assistance in the obtention of monoclonal antibody and immunohistochemistry analysis, respectively. toantibody blocks uptake of oxidized LDL by macrophages and localizes to atherosclerotic lesions in vivo. Arterioscler Thromb Vasc Biol 2001; 21: 1333-1339.

13. Vedie B, Myara I, Pech MA, Maziere JC, Maziere C, Caprani $A$, et al. Fractionation of charge-modified low density lipoproteins by fast protein liquid chromatography. J Lipid Res 1991; 32: 1359-1369.

14. Fassina G, Verdoliva A, Odierna MR, Ruvo M, Cassini G. Protein $A$ mimetic peptide ligand for affinity purification of antibodies. J Mol Recognit 1996; 9: 564-569.

15. Itabe $H$, Yamamoto $H$, Suzuki $M$, Kawai $Y$, Nakagawa $Y$, Suzuki A, et al. Oxidized phosphatidylcholines that modify proteins. Analysis by monoclonal antibody against oxidized low density lipoprotein. J Biol Chem 1996; 271: 3320833217.

16. Itabe $\mathrm{H}$, Yamamoto $\mathrm{H}$, Imanaka $\mathrm{T}$, Shimamura $\mathrm{K}$, Uchiyama $\mathrm{H}$, Kimura J, et al. Sensitive detection of oxidatively modified low density lipoprotein using a monoclonal antibody. $J$ Lipid Res 1996; 37: 45-53.

17. Vermeer AW, Norde W, van Amerongen A. The unfolding/ denaturation of immunogammaglobulin of isotype $2 b$ and its $F(a b)$ and $F(c)$ fragments. Biophys J 2000; 79: 2150-2154.

18. Laemmli UK. Cleavage of structural proteins during the assembly of the head of bacteriophage T4. Nature 1970; 227: 680-685.

19. Paigen B, Morrow A, Holmes PA, Mitchell D, Williams RA. Quantitative assessment of atherosclerotic lesions in mice. Atherosclerosis 1987; 68: 231-240.

20. Reis MM, Higuchi ML, Aiello VD, Benvenuti LA. Growth factors in the myocardium of patients with chronic chagasic cardiomyopathy. Rev Soc Bras Med Trop 2000; 33: 509518.

21. Villablanca A, Lubahn D, Shelby L, Lloyd K, Barthold S. Susceptibility to early atherosclerosis in male mice is mediated by estrogen receptor alpha. Arterioscler Thromb Vasc Biol 2004; 24: 1055-1061.

22. Baeyens WR, Schulman SG, Calokerinos AC, Zhao Y, Garcia Campana AM, Nakashima K, et al. Chemiluminescence-based detection: principles and analytical applications in flowing streams and in immunoassays. J Pharm Biomed Anal 1998; 17: 941-953.

23. Pereira EC, Bertolami MC, Faludi AA, Salem M, Bersch D, Abdalla DS. Effects of simvastatin and L-arginine on vasodilation, nitric oxide metabolites and endogenous NOS inhibitors in hypercholesterolemic subjects. Free Radic Res 
2003; 37: 529-536.

24. Tabas I. Consequences and therapeutic implications of macrophage apoptosis in atherosclerosis: the importance of lesion stage and phagocytic efficiency. Arterioscler Thromb Vasc Biol 2005; 25: 2255-2264.

25. Liu J, Thewke DP, Su YR, Linton MF, Fazio S, Sinensky MS. Reduced macrophage apoptosis is associated with accelerated atherosclerosis in low-density lipoprotein receptor-nul mice. Arterioscler Thromb Vasc Biol 2005; 25: 174-179.

26. Arai S, Shelton JM, Chen M, Bradley MN, Castrillo A, Bookout $A L$, et al. A role for the apoptosis inhibitory factor AIM/ Spalpha/Api6 in atherosclerosis development. Cell Metab 2005; 1: 201-213.

27. Schiopu A, Bengtsson J, Soderberg I, Janciauskiene S, Lindgren S, Ares MP, et al. Recombinant human antibodies against aldehyde-modified apolipoprotein $\mathrm{B}-100$ peptide se- quences inhibit atherosclerosis. Circulation 2004; 110: $2047-$ 2052.

28. Li H, Cybulsky MI, Gimbrone MA Jr, Libby P. An atherogenic diet rapidly induces VCAM-1, a cytokine-regulatable mononuclear leukocyte adhesion molecule, in rabbit aortic endothelium. Arterioscler Thromb 1993; 13: 197-204.

29. Sakai A, Kume N, Nishi E, Tanoue K, Miyasaka M, Kita T. Pselectin and vascular cell adhesion molecule- 1 are focally expressed in aortas of hypercholesterolemic rabbits before intimal accumulation of macrophages and $\mathrm{T}$ lymphocytes. Arterioscler Thromb Vasc Biol 1997; 17: 310-316.

30. Vielma S, Virella G, Gorod A, Lopes-Virella M. Chlamydophila pneumoniae infection of human aortic endothelial cells induces the expression of FC gamma receptor II (FcgammaRII). Clin Immunol 2002; 104: 265-273. 